\title{
The Double Duty of the Sakha "Passive"
}

\author{
Tamisha L. Tan \& Niels Torben Kühlert*
}

\begin{abstract}
This paper argues that the Sakha passive morpheme -IlIn- is the fossilised outcome of a bimorphemic 'passive of passive' construction still found in Modern Turkish. While this reanalyzed form is surface homophonous between passive and impersonal functions, we show that the two uses can be differentiated via several syntactic diagnostics and that the Sakha impersonal construction supports the existence of a syntactically-projected impersonal pronoun that may serve as Case Competitor and control/be controlled PRO. At the same time, the diachronic account presented in this paper has important implications for the reconstruction of the Common Turkic voice system and the status of ImpersP and VoiceP as distinct functional projections, instead suggesting that impersonal passive constructions involve the iteration of VoiceP.
\end{abstract}

Keywords. Turkic; passives; impersonals; Sakha; voice alternations; VoiceP

1. Introduction. In Turkish, doubling the passive morpheme $-I l$ - productively results in an impersonal passive interpretation (Özkaragöz 1986, Kiparsky 2013, Murphy 2014, a.o.): ${ }^{1}$

\section{Harp-te vur-ul-un-ur war-LOC shoot-PASS-PASS-AOR}

'One is shot (by one) in war'
(Özkaragöz 1986: 77, ex. 1c)

Recent work by Legate \& Akkus (2017) and Legate et al. (2020) argues that this doubling involves two functionally distinct but homophonous morphemes which head distinct projections stacked atop each other: namely, ImpersP and VoiceP. In the related Northern Siberian language Sakha, the default passive marker has the form -IlIn-:

(2) Min tut-ulun-n-um

1 SG catch-PASS-PST-1SG

'I was caught (just now.)'

We argue that Sakha has fossilised the originally doubled form in (1) and reanalysed it as a monomorphemic element, which nevertheless retains its homophonous but structurally distinct dual function as both a passive and impersonal head. Our paper not only presents a novel account of the diachronic origin of the Sakha morpheme -IlIn- with implications for the Common Turkic voice system, but also extends existing diagnostics teasing apart impersonal and passive constructions. In addition, our findings support the existence of a syntactically-projected impersonal pronoun which can serve as Case Competitor and control/be controlled PRO. Finally, we argue that the historical developement of the -IlIn-morpheme in Sakha suggests that

\footnotetext{
* Above all, we would like to thank Daria Boltokova and her family for sharing their language with us. We are also grateful to Faruk Akkuş, Jonathan Bobaljik, Ian Kirby, Milena Šereikaite, and the audiences of the Tu+5 Workshop and $94^{\text {th }}$ Annual LSA Meeting for their insightful comments and feedback. Authors: Tamisha L. Tan, Harvard University \& Nanyang Technological University (tamishaltan@g.harvard.edu) and Niels Torben Kühlert, Harvard University (nielstorbenkuehlert@g.harvard.edu).

${ }^{1}$ Abbreviations that differ from the Leipzig Glossing Rules: AOR - aorist; IMP - impersonal; IMPV - imperative; R.PST - remote past
} 
impersonal passives involve the iteration of a single functional projection, rather than two distinct ones, such that ImpersP may be another flavour of VoiceP.

Section 2 provides an overview of the passive morpheme in Sakha, outlining its phonological and morphosyntactic distribution and situating it in comparison to passive morphology across the wider Turkic family. Turning then to the impersonal usage of -IIIn-, Section 3 presents several key syntactic diagnostics which differentiate between the passive and impersonal constructions in Sakha. Section 4 proposes two underlying structures which derive these syntactic differences, while Section 5 lays out the diachronic development of the Sakha (and Common Turkic) voice system. Section 6 concludes.

\section{Distribution of the passive morpheme.}

2.1. On ITS Allomorphy. The passive morpheme in Sakha is a suffix with the basic shape $-I l I n-.^{2}$ Its base form can best be seen in the imperative:
a. tut- $\varnothing$
b. tut-ulun- $\varnothing$
catch-IMPV
'catch!'
catch-PASS-IMPV
'be caught!'

Traditionally, this morpheme has been described as alternating between two surface allomorphs: - $n$ - following stems ending with a vowel and -IlIn- after stems ending with a consonant (Stachowski \& Menz 1998: 424, Vinokurova 2005: 336, Ebata 2013: 18). Danilova \& Vinokurova (2015) identify a third form -nIlIn-, which they claim is the -IlIn- allomorph pleonastically appended to the $-n$ - allomorph as 'disambiguation.' However, our data and analysis instead suggest that the difference between $-n$ - and $-(n) I l I n$ - is syntactic rather than phonological, with -(n)IlIn- being the only true reflex of the passive morpheme. The surface alternation between forms with and without $-n$ - is demonstrated below:
a. min tut-ullu-but-un
1SG catch-PASS-R.PST-1SG
'I was caught (a while ago).'
b. min sie-nilli-bit-im
1 SG eat-PASS-R.PST-1SG
'I was eaten (a while ago).'

The variation between -IIIn- and -nIIIn- does not derive from pleonastic stacking but simple - $n$ insertion following vowel-final stems, directly mirroring other vowel hiatus resolution patterns in the language such as with accusative morpheme $-(n) I-$ :

$$
\begin{aligned}
& \text { a. } \dot{i t}-\dot{i} \\
& \text { dog-ACC } \\
& \text { 'dog' }
\end{aligned}
$$
b. kinige-ni
book-ACC
'book'

The morpheme is also phonologically-conditioned by following elements, surfacing with geminated /1/ as -IllI- before non-alveolar consonants and -Ill- with syncopation before vowels: ${ }^{3}$

\footnotetext{
${ }^{2}$ The vowels in this morpheme are subject to vowel harmony in which they assimilate to the $[ \pm$ front $]$ and $[ \pm$ round] features of the last syllable of the stem. $<\mathrm{I}>$ indicates that the vowel is always [+high].

${ }^{3}$ There is inter-speaker variation in regards to the outcome of $/ \mathrm{j} /$-final roots. While both Danilova \& Vinokurova (2015) and Stachowski \& Menz (1998) state that final /j/may be dropped, followed by a syncopated -lIn-, this syncopation was categorically rejected by our consultant.
} 
a. tut-ullu-ma

catch-PASS-NEG.IMPV

'Don't be caught!' b. kiliep sie-nill-er

bread eat-PASS-AOR.3SG

'Bread is eaten.'

The non-geminated/syncopated form shows up elsewhere (i.e. word-finally and before alveolar consonants), as in (3). In Section 5.2, we will discuss how this phonological distribution can be obtained by assuming an underlying /-IlIl-/ input. The alternative analysis in prior literature may stem from the fact that some verbs cannot be passivised, instead using an anti-causative morpheme that appears as - $n$ - following a vowel and -In-following a consonant. One such example is the vowel-final stem $a h a-$ 'eat', which can only take the semantically similar anticausative instead of the passive:

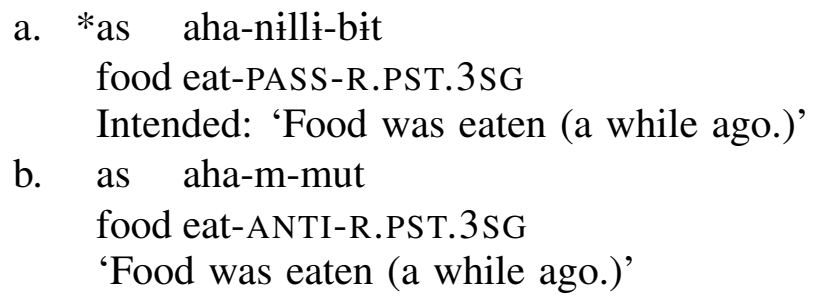

a. *as aha-nilli-bit food eat-PASS-R.PST.3SG Intended: 'Food was eaten (a while ago.)'

b. as aha-m-mut food eat-ANTI-R.PST.3SG

'Food was eaten (a while ago.)'

(Passive)

(Anti-causative)

Evidence that $-n$ - and -IlIn- are not true allomorphs comes from their contrasting ability to occur with agent-oriented adverbs and purpose clauses and the existence of minimal pairs: ${ }^{4}$
a. sulus eh-ilin-n-e
star explode-PASS-PST-3SG
'The star was exploded'
b. sulus eh-in-n-e
star explode-ANTI-PST-3SG
'The star exploded'

(Passive)

(Anti-causative)

In (8-a), the explosion must have been caused by an implicit agent (e.g. aliens). In (8-b), the explosion is more the result of a natural phenomenon like a supernova.

2.2. ON ITS MORPHOSYNTACTIC DISTRIBUTION. Having established the phonological shape of the passive morpheme in various conditioning environs, we turn now to its morphosynatactic behavior. Consider the following active $\sim$ passive alternation:
a. uol tynnyk-ter- $\dot{\mathfrak{i}}$ aljat-t-a
boy window-PL-ACC break-PST-3SG
'A boy broke the windows'
b. tynnyk-ter- $(* \mathrm{i}) \quad$ aljat-ilin-n-ilar
window-PL- $(*$ ACC $)$ break-PASS-PST-3PL
'Windows were broken'

(Active)

(Passive)

Passive constructions in Sakha behave largely as expected, involving suppression of the agent (i.e. uol 'boy') and promotion of the theme (i.e. tynnyk-ter 'windows'). This results in the loss of accusative marking in (9-b). Under a configurational approach to case assignment (Baker 2015), where accusative case is dependent and assigned in the presence of a higher c-commanding

\footnotetext{
${ }^{4}$ A reviewer helpfully suggests testing 'by-itself' phrases, parallel to Turkish kendi kendine, which should be able to occur with anti-causatives but not passives. Future work would test the availability of beje- 'self' DPs, which Vinokurova (2005) notes can add 'spontaneously' or 'without outside help' semantics.
} 
DP, these passive constructions hence involve a single argument DP. As expected, the passive verb agrees with the promoted theme for person and number, taking the 3PL suffix -ilar.

However, one unexpected feature of these constructions is their inability to take 'by-phrases', in the sense that there is no way to re-introduce the agent via an oblique DP. As first noted by Ebata (2013), this directly disputes Stachowski \& Menz's (1998: 432) claim that the agents can be expressed using the instrumental suffix -Inan:
a. *tynnyk uol-unan aljat-illi-bit window boy-INS break-PASS-R.PST.3SG
Intended: 'The window was broken by the boy'
b. *min polisija-lar-inan tut-ulun-n-um 1SG police-PL-INS catch-PASS-PST-1SG Intended: 'I was caught by policemen'

(Ebata 2013: 23)

This is in contrast to Turkish, where passive constructions may re-introduce agents using a PP:
a. Ali kitab-I hizli oku-du.
Ali book-ACC quick read-PST.3SG
'Ali read the book quickly'
b. kitap (Ali tarafindan) hizlı oku-n-du. book Ali by quick read-PASS-PST.3SG
'The book was read (by Ali) quickly.'

(Legate et al. 2020: 4, ex. 2)

Ebata suggests that only inanimate elements may be re-introduced as instrumentals:
a. tynnyk mah-inan aljat-illi-bit window tree-INS break-PASS-R.PST.3SG
'The window was broken using wood.'
b. oju:r-ga uol mah-inan tarba-nilli-bit
forest-LOC boy tree-INS scratch-PASS-R.PST.3SG
'In the forest, the boy was scratched using wood'

Note especially the minimal pair in (10-a) and (12-a), in which the only point of variation is the animacy of the instrumentally-marked noun. Contra Ebata, we argue the actual generalisation is that any agent 'by-phrase' is impossible in passive constructions; what he takes to be inanimate DPs with AGENT $\theta$-roles are in fact InSTRUMENTS. This accounts for the supposed animacy distinction. Consider the following passive construction:
(13) *min tayan-im
d3ulus-unan u:n-ullu-but
1SG clothes-1SG.POSS djulus-INS stretch-PASS-R.PST.3SG
'My clothes were stretched (\#using/*by Djulus)'

The only grammatical interpretation of the instrumental phrase in (13) is if Djulus is being used as a tool with which to stretch the clothes, and not as the agent doing the stretching. Thus, it is clear that Djulus can only bear an INSTRUMENT theta-role, and not an AGENT role; Section 4 will elaborate on this observation with reference to passives' underlying structure. Another cross-linguistic oddity of Sakha passives will be highlighted in Section 3.2.4, where they are shown to be incompatible with agent-oriented adverbs, again suggesting that the suppression of agents in Sakha appears to be stronger or more extreme than in most languages. 
2.3. The PAssive Morpheme in Turkic. Throughout the Turkic languages, the passive morpheme is almost always a monosyllabic morpheme that is usually reflected by $-l$ - or its dissimilatory allomorph $-n$ - occurring after stems endings with $-l-.^{5}$

\begin{tabular}{|c|c|c|c|c|c|c|}
\hline & \multicolumn{2}{|c|}{ Oghuz } & Karluk & \multicolumn{2}{c|}{ North Siberian } & South Siberian \\
\hline \hline Proto-Turkic & Turkish & Turkmen & Uzbek & Dolgan & Sakha & Old Turkic \\
\hline$*_{-}(I) l-$ & $-(I) l / n-$ & $-(I) l / n-$ & $-(I) l / n-$ & $-I l I n-$ & $-I l I n-$ & $-(X) l-$ \\
\hline
\end{tabular}

\begin{tabular}{|c|c|c|c|c|c|}
\hline Oghur & \multicolumn{5}{|c|}{ Kipchak } \\
\hline Chuvash & Tatar & Kazakh & Nogai & Kyrghyz & Crim. Tatar \\
\hline$-\left(\AA \AA^{\prime}\right) n-$ & $-(\mathrm{E}) 1 / \mathrm{n}-$ & $-(I) l / n-$ & $-(I) l / n-$ & $-(I) l-$ & $-(I) l / n-$ \\
\hline
\end{tabular}

Table 1. Passive Morpheme throughout Turkic

Only Sakha and the closely related Dolgan have a disyllabic reflex -IlIn-, which nevertheless behaves mostly like a normal passive. This seemingly-doubled appearance is striking and has gone largely unexplained, with the exception of Böhtlingk's (1851: 288) suggestion that -IlIninvolves the reflexive morpheme - In- stacked on top of the passive morpheme -Il-. However, the semantics of such a combination do not seem to lend itself to reanalysis as a simple passive. Instead, recent work on Turkish 'passives of passives' suggests a more enticing hypothesis: that it is an impersonal morpheme appended to a homophonous passive morpheme.

\section{Distribution of the impersonal morpheme.}

3.1. TuRKish. As discussed by Legate \& Akkus (2017), while the Turkish passive morpheme is fine with by-phrases (11-b) and non-human interpretation, it is ungrammatical with pseudoincorporated objects, unaccusative verbs, and verbs which take oblique arguments. In contrast, the exact opposite pattern obtains with the homophonous impersonal morpheme, which disallows by-phrases and non-human interpretation but allows the other aforementioned contexts. Thus, (14) with unaccusative boğul- 'drown' is only fine with an impersonal interpretation and without a by-phrase, while (15) is bad since it involves a non-human agent:

$\mathrm{Bu}$ göl-de (*insan-lar tarafindan) boğul-un-ur

this lake-LOC person-PL by drown-PASS-AOR

'One can drown in this lake. / It can be drowned in this lake.' (Özsoy 2009: 5, ex. 4)

*Çöl-ler-de hısla-n-1yor.

desert-PL-LOC hiss-IMP-PROG

'One hisses in the deserts.'

(Legate et al. 2020: 12, ex. 22b)

Furthermore, impersonal agents may both control and be controlled PRO, unlike in passives:
a. $\mathrm{IMP}_{\mathrm{i}}\left[\mathrm{PRO}_{\mathrm{i}}\right.$ otobüs-e bin-il-mek] iste-n-di
bus-DAT board-IMP-INF] want-IMP-PST
'One $\mathrm{i}_{\mathrm{i}}$ wanted $\mathrm{PRO}_{\mathrm{i}}$ to board the bus.'

(Legate et al. 2020: 14, ex. 27a)

5 cf. Berta (1998), Boeschoten (1998), Clark (1998), Csató (1998), Kirchner (1998a,b), Róna-Tas (1998), Schönig (1998a,b), Erdal (2004), Kavitskaya (2010). While Old Turkic at its earliest stages does not have an attested passive $-(X) l-$, it was already pervasive in Uighur (Erdal 1991: 651). Since other Turkic languages not descendent from Old Turkic also have this passive morpheme, we remain satisfied with the traditional reconstruction of $*(I) l$. What is important for our analysis, is that Proto-Turkic had some middle/passive-like element expressed by $*(I) l$. 

b. *Hasan [kitap hızlı oku-n-mak] iste-di.
Hasan [book quick read-PASS-INF] want-PST
Intended: 'Hasan wanted to read the book quickly.' (Legate \& Akkus 2017: ex. 9)

Earlier analyses of the impersonal function of - Il- suggest that it involves passives where the agent has been demoted without promotion of the theme to subject position, producing an impersonal passive (Özkaragöz 1986, Kiparsky 2013). Legate \& Akkus instead argue that the impersonal morpheme is functionally distinct from the passive, such that the sentences in (14) and (16-a) are active voice constructions with a null impersonal pronoun in Spec, VoiceP and no demotion of the agent. In Section 4, we will adopt this latter account in our analysis of Sakha impersonals. Before that, however, we will build on the diagnostics used to differentiate (active) impersonal and passive constructions in Turkish to show that both functions also exist in complementary distribution in Sakha.

3.2. IMPERSONALS IN SAKHA. The constructions bearing impersonal meaning with the apparent passive morpheme have been identified by Vinokurova (2005: 336) and Ebata (2013: 22) as 'syntactic passives' or 'impersonal passives' respectively. In this paper, we specifically draw a distinction between the active impersonal, and passive impersonal, and thus eschew the somewhat muddied terminology of the previous literature. Thus, sentences in which the agent of the construction is impersonal comprise the active impersonal, while sentences in which the theme of the construction is impersonal comprise the passive impersonal. Crucially, -IIIn- can only instantiate the former active type, as will be shown by the diagnostics below; the absence of the latter (equivalent to the Turkish example (1)) will be discussed in Section 4.1.

3.2.1. Accusative Retention And 3Sg Agreement. Accusative marking on the theme cannot be retained in passive constructions, but can in impersonal constructions:
a. sir ahat-ill-ar
earth feed-PASS-AOR.3SG
'The earth is fed'
b. sir-i ahat-ill-ar
earth-ACC feed-IMP-AOR.3SG
'One feeds the earth'

(Passive)

(Impersonal)

Semantically, the difference between the sentences in (17) is that the passive sentence is a characterising statement evoking the general state of the earth. In contrast, the impersonal construction strongly requires some human agent to be conducting the action of feeding (i.e. sowing.) In conjunction with this, passivised verbs show agreement with the promoted theme, but impersonal verbs can only take default 3 SG agreement. Thus, accusative retention and any non-3SG morphology on the verb are in complementary distribution:
a. yges-ter- $(* \mathbf{i}) \quad$ keh-illi-bet-ter tradition-PL-(*ACC) break-PASS-NEG.AOR-3PL 'Customs are not broken'
b. yges-ter-i keh-illi-bet tradition-PL-ACC break-IMP-NEG.AOR.3SG 'One does not break customs'

(Passive)

(Impersonal) 
This requirement for default agreement is characteristic of impersonal constructions crosslinguistically (Egerland 2003). Taken together, this complementary distribution is strong evidence for the fact that impersonals do not involve promotion of the theme but instead retain some $3 \mathrm{SG}$ agent in subject position, unlike passives. ${ }^{6}$

3.2.2. IntRAnsitivity. A well known diagnostic distinguishing between unaccusative and unergative verbs is that the former cannot be passivised, while the latter can. This is also true of passivisation in Sakha. However, while unaccusative verbs like $t i: j$ - 'arrive' cannot be passivised with -IlIn-, they can become impersonal:
a. *kini-ler massi:na-nan ikki su:kka-nan ti:j-ill-e-ler
3-PL car-INS two day-INS arrive-PASS-AOR-3PL
Intended: 'They are reached by car in two days.'
b. massì:na-nan ikki su:kka-nan ti:j-ill-er
car-INS two day-INS arrive-IMP-AOR.3SG
'One can arrive [there] by a car in two days'.

(Passive)

(Impersonal)

Only constructions which have an underlying theme available for promotion can be passivised. However, this requirement does not hold for impersonals, again indicating a lack of promotion.

3.2.3. Human Agent. Just like in Turkish (15), verbs which select for semantically inanimate or non-human agents cannot form impersonals:
a. *sa:s till-ill-ar
spring bloom-IMP-AOR.3SG
Intended: 'In spring, one blooms'
b. \#kihin køt-ull-er
winter fly-IMP-AOR.3SG
Intended: 'In winter, one flies'

(Flowers)

The unaccusative verb titl- 'bloom' in (20-a) requires an impersonal construal. However, this impersonal interpretation is blocked because the salient subject is flowers, resulting in ungrammaticality. Similarly, (20-b) is unavailable as an impersonal if the intended context is birds migrating for the winter, but can be marginal if one coerces a reading of humans flying for travel. This clearly shows that the requirement is not one of animacy, but of humanhood.

3.2.4. AgEnt Adverbs. In line with the requirement for a human agent, impersonals can always take agent-oriented adverbs like sorujan 'intentionally', while passives cannot:
a. *kiliep-ter sorujan buhar-ill-iaq-tara bread-PL intentionally bake-PASS-FUT-3PL
Intended: 'Breads will intentionally be baked'
b. kiliep-ter-i sorujan buhar-ill-iaq-a
bread-PL-ACC intentionally bake-IMP-FUT-3SG
'One will intentionally bake breads'

(Passive)

(Impersonal)

\footnotetext{
${ }^{6}$ Baker (2015: $\left.§ 5.3\right)$ argues that accusative retention in Sakha is evidence that even weak implicit arguments (i.e. the demoted agent of passives) can serve as case competitors for dependent case assignment. Our analysis, where constructions with accusative retention are impersonal and those without are passive, instead show that only strong implicit arguments (i.e. the silent impersonal pronoun) may be case competitors, not weak ones. This would put Sakha in line with languages like Finnish and Quechua on Baker's implicational hierarchy of nominal expressions.
} 
One might suspect that this infelicity is caused by the inanimacy of kiliep 'bread'. However, consider the following example:

(22) it sorujan imer-ilin-n-e

dog intentionally pet-IMP-PST-3SG

'One intentionally pet the dog' NOT 'The $\operatorname{dog}_{\mathrm{i}}$ was pet, as $\mathrm{it}_{\mathrm{i}}$ intended'

On the surface, this construction seems homophonous between impersonal and passive construals. However, only the impersonal reading is licit, in which the petter is acting intentionally; it cannot be that the dog was seeking to be pet (i.e. the adverb is necessarily agent-oriented, not subject-oriented.) Hence, even with an animate theme, sorujan forces an impersonal reading. This is also the case with human arguments:

uol(-u) sorujan tarba-nill-iaq-a

boy(-ACC) intentionally scratch-IMP-FUT-3SG

'One will intentionally scratch the boy'

NOT 'The boy ${ }_{i}$ will be scratched, as he intended'

This emphasises that impersonal constructions have an agent which agent-oriented adverbs can modify, while passive constructions do not. Interestingly, a reviewer highlights that regular passives in Turkish are compatible with agent-oriented adverbs like kasten 'intentionally'; indeed, Sakha is cross-linguistically unusual in prohibiting these adverbs in passive constructions. This may suggest that the demoted agent in Sakha passives is further removed or more inaccessible than in other languages like Turkish. We leave the investigation of this to future work.

3.2.5. ExCEPtional CASE MARKing. Vinokurova (2005: 261) observes that Sakha allows the subjects of finite clausal complements to be marked accusative as a form of ECM (i.e. 'raising-to-object'):

min ehigi-ni [bygyn kiaj-iaq-sit dien] erem-mit-im

$1 \mathrm{SG} 2 \mathrm{PL}-\mathrm{ACC}$ today win-FUT-2PL COMP hope-R.PST-1SG

'I hoped you would win today'

(Vinokurova 2005: 361)

Baker \& Vinokurova (2010) analyse these as embedded subjects crossing a clause boundary, becoming a case competitor for the matrix subject and receiving dependent case (Baker 2015). For the purposes of this paper, we assume this to be the correct analysis. ${ }^{7}$ ECM configurations thus provide key evidence for the syntactic structure of impersonal constructions; crucially, the matrix clause of an ECM construction may be impersonal but not passive:

(25) *mi:gin [bygyn kiaj-ia-m dien] eren-ill-e-bin

1SG.ACC today win-FUT-1SG COMP hope-PASS-AOR-1SG

Intended: 'I am hoped to win today'

(Passive)

(26) kini-ler-i [bygyn kiaj-iaq-qara dien] eren-ill-er

3-PL-ACC today win-FUT-3PL COMP hope-IMP-AOR.3SG

'One hopes that they win today'

(Impersonal)

Under a configurational approach to case, this suggests that the impersonal DP in the matrix

${ }^{7}$ Unlike cf. Kornfilt \& Preminger (2015), who dispute how nominative case is assigned in these constructions. 
clause is syntactically projected, c-commanding the raised element. In contrast, no such higher (agent) DP exists to assign accusative case in passive constructions.

3.2.6. Control. Finally, passives and impersonals also differ in their behaviour in non-finite clauses. As in Turkish (16), the impersonal argument can both control and be controlled PRO:

$$
\begin{aligned}
& \text { a. } \quad \mathrm{IMP}_{\mathrm{i}}\left[\mathrm{PRO}_{\mathrm{i}} \text { seri:-ge } \varnothing \text { l-yll-y } \varnothing-\mathrm{n}\right] \text { basar-illi-bat } \\
& \text { war-DAT die-IMP-FUT-CVB want-IMP-NEG.AOR.3SG } \\
& \text { 'One }{ }_{i} \text { does not want } \mathrm{PRO}_{\mathrm{i}} \text { to die in war' } \\
& \text { b. } \operatorname{IMP}_{\mathrm{i}}\left[\mathrm{PRO}_{\mathrm{i}}\right. \text { massinan-nan ti:j-ill-ie-n] tapta-nill-ar } \\
& \text { car-INS arrive-IMP-FUT-CVB love-IMP-AOR.3SG } \\
& \text { 'One }{ }_{\mathrm{i}} \text { loves } \mathrm{PRO}_{\mathrm{i}} \text { to arrive by car' }
\end{aligned}
$$

(Impersonal)

In contrast, the promoted theme of a matrix passive cannot control PRO:

min [kinige a:s-illi-an] basar-a-bin

$1 \mathrm{SG}$ book read-PASS-CVB want-AOR-1SG

'I want the book to be read (*by me)'

(Passive)

While (28) is fine with the reading that the speaker wants the book to be read by someone else/in general, it is wholly ungrammatical under the interpretation that the speaker wants to read the book themselves. One also cannot passivise both the matrix and embedded clause:

$$
\begin{aligned}
& \text { *min [søbule:-nill-ia-n] basa-ill-a-bin } \\
& \text { 1SG like-PASS-FUT-CVB want-PASS-AOR-1SG } \\
& \text { Intended: 'I am wanted to be liked (by myself/someone else)' }
\end{aligned}
$$

(29) is equally bad if the speaker is wanted to be liked by someone else, or if the speaker is wanted to be liked by themselves. All this suggests that the impersonal pronoun is syntactically projected in a way the promoted theme of the passive is not.

3.3. Summary. These diagnostics all point to a difference in how the syntactic subject is derived: in impersonals, the subject is a (silent) human agent, available for case-assignment and control. In passives, this subject is derived by promoting and raising the theme argument, while the agent is demoted and inaccessible for the aforementioned relationships. We thus expect two different underlying structures for these nearly string-identical constructions.

4. Morphosyntactic structure. We assume the distinction between feature interpretability and valuation (Pesetsky \& Torrego 2007), where uninterpretable features must be deleted before Spell-Out via AGREE with a relevant interpretable counterpart, which also results in valuation of an unvalued feature. Following Legate \& Akkus's (2017) analysis of Turkish, we propose that the structural difference between Sakha passives and impersonals is as follows.

$$
\begin{aligned}
& \text { a. min tut-ullu-a-bin } \\
& \text { 1SG catch-PASS-AOR-1SG } \\
& \text { 'I am caught.' } \quad \text { (Passive) }
\end{aligned}
$$


b.

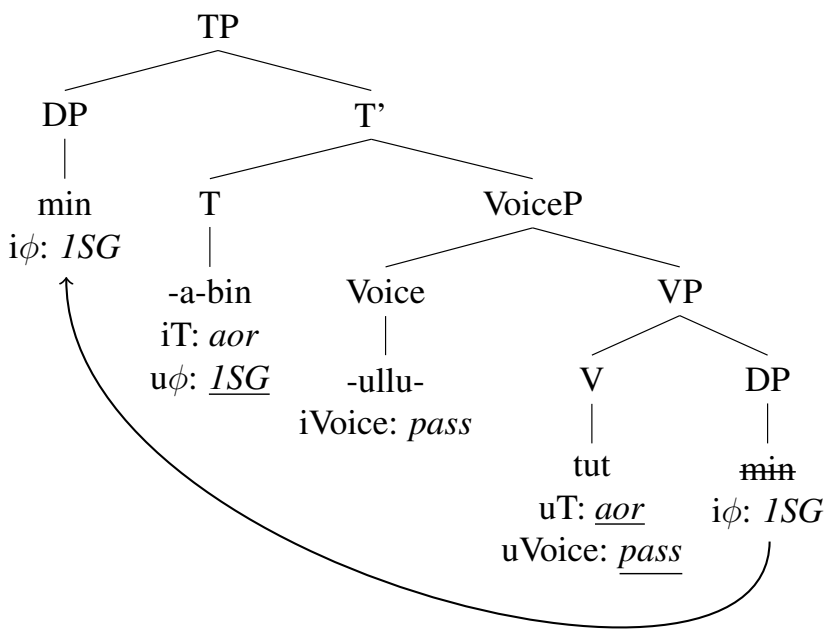

In a canonical passive, VoiceP fails to introduce an external argument in its specifier (Legate 2014). The single theme DP raises to subject position in Spec, TP, agreeing with T (which surfaces with non-3SG agreement as appropriate.) As the sole available DP, it can only receive nominative case; furthermore, while this DP has no restrictions on animacy, it cannot co-occur with agent-oriented adverbs due to its THEME $\theta$-role. Finally, the syntactic absence of a ccommanding agent DP prevents ECM on elements raised into passivised clauses and also cannot be controlled. At the same time, the verb simply successively head-moves through Voice and $\mathrm{T}$ to check its voice and tense features, resulting in suffixation of the relevant morphemes. Turning now to the structure of an impersonal:

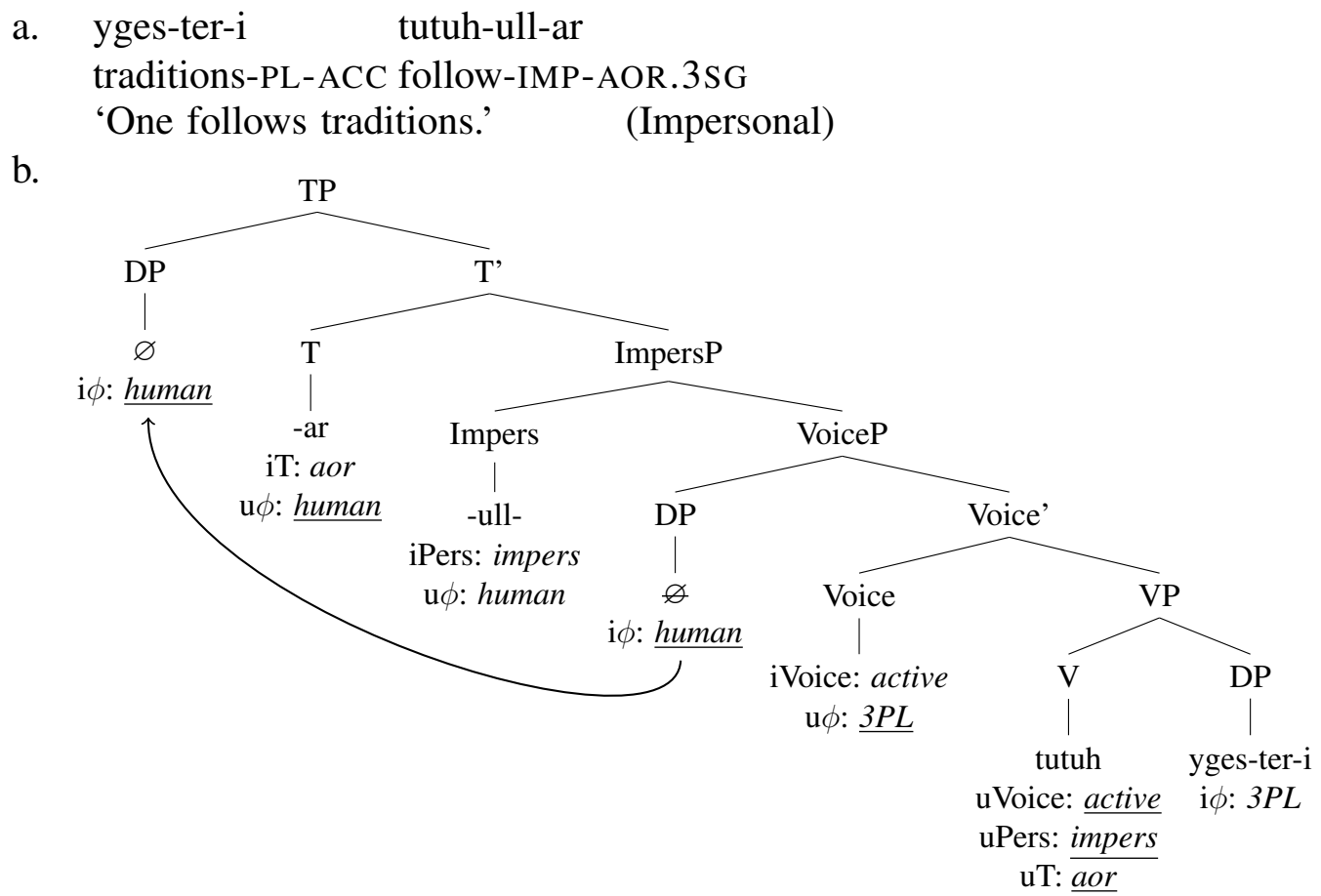

Impersonal constructions are active, with a silent pronoun first-merged in either Spec, VoiceP (as transitive/unergative agents) or as the complement of VP (as unaccusative themes). Following Legate \& Akkus (2017), this pronoun is licensed by an impersonal projection which 
confers upon it a [+human] interpretation restriction via $\phi$-feature AGREE. The pronoun then raises to Spec, TP, obligating default $3 \mathrm{SG}$ agreement on $\mathrm{T}$ even if the transitive theme is non3SG. In transitive and ECM structures, the impersonal pronoun c-commands this theme, resulting in accusative marking on the lower DP. Finally, because there is a syntactically-projected agent, agent-oriented adverbs and Control relationships are available. As in (30-a), the verb head-moves through the higher projections; this time, however, it also moves into Impers. Crucially, the fact that instrumental case-marked DPs are available in impersonal constructions as in (19-b) and elsewhere is good evidence that these obliques do not introduce DPs with AGENT $\theta$-roles but INSTRUMENT ones, since impersonals already have a distinct syntacticallyprojected pronoun bearing the AGENT role.

4.1. Motivating ImPersP. Legate \& Akkus (2017) argue that overt evidence for ImpersP comes from the 'passive of passive' constructions as in (1), in which the morpheme -Il- is apparently doubled and the theme is impersonal (and must be human) rather than the agent:

Orman-da (yılan-lar tarafindan) sok-ul-un-ur.

forest-LOC snake-PL by bite-PASS-IMP-AOR

'In the forest, one is bitten (by the snakes).' (Legate et al. 2020: 27, ex. 59a)

However, any attempt to stack the Sakha passive/impersonal morpheme -IlIn- in the phonologically expected manner based on Section 2.1 results in extreme marginality:
a. ??qos-ko yøret-ill-ill-er
room-DAT teach-PASS?-IMP?-AOR.3SG
'In the room, one has to be taught.'
b. ??ilim-inen tut-ull-ull-ar
net-INSTR catch-PASS?-IMP?-AOR.3SG
'One is caught in a net.'

While -IIIn- clearly produces distinct active impersonal and passive constructions, it lacks the ability form passive impersonals in the same way as doubled Turkish -Il-. Given that the surface form of -IlIn- looks bimorphemic, this gap is puzzling - why would the morpheme not retain the function of the construction it was 'frozen' and taken over from? We believe that a diachronic explanation not only sheds light on this issue, but furthermore suggests that ImpersP and VoiceP are not distinct projections but rather an iterated VoiceP of different 'flavours." 8

5. Diachrony. Building off the Sakha voice system, we propose that the following morphemes can be reconstructed for at least Common Turkic: firstly, there is the passive morpheme $*_{-} I l-$, with a dissimilatory allomorph $*$-In- following $* l$ final stems. Secondly, we can reconstruct a homophonous active impersonal morpheme *-Il-, given its attestation in Turkish (cf. Section 3.1) and Uzbek:

$$
\begin{aligned}
& \text { Počta-ga qanday bor-il-adi } \\
& \text { post.office-DAT how go-IMP-AOR.3SG } \\
& \text { 'How can one go to the post office?' }
\end{aligned}
$$

(Boeschoten 1998: 364)

This sentence must be impersonal since the verb selects for an oblique argument. Finally, we

\footnotetext{
${ }_{8}^{8}$ Note that this would not lead to multiple external arguments, as only Voice ${ }_{\mathrm{ACTIVE}} \mathrm{P}$ can introduce an argument in its specifier; we assume that Voice IMPERS $\mathrm{P}$, like Voice PASS $\mathrm{P}$, cannot. We thank a reviewer for raising this concern.
} 
can reconstruct a productive doubling of these aforementioned morphemes as $*$-Il-In- (with synchronic dissimilation) to derive a passive impersonal. ${ }^{9}$ Turkish is conservative in preserving this three-way system exactly as described above. At least some languages (including Uzbek) continue the two-way passive and active impersonal functions, although further investigation must be done on this point. However, most languages subsequently lost the third option of productive doubling. With this picture in mind, we can account for the development of the Sakha passive morpheme as follows.

5.1. Development in SAKHA. We argue that the impersonal passive was reanalyzed as a passive. The bridging context for this shift is as follows: due to Sakha being a pro-drop language, a passive impersonal in the earlier language could have easily been mistaken for a personal passive with a silent $3 \mathrm{SG}$ subject:
a. tut-ul-un-n-a.
catch-PASS-IMP-PST-3SG
'(Some)one was caught'
b. (kini) tut-ulun-n-a
(3SG) catch-PASS-PST-3SG
'He was caught.'

(Pre-Sakha: Impersonal passive)

The semantic overlap of the two sentences in (35) is substantial. In each, the theme identifies a human who has been caught. Without an overt subject, it is impossible to tell from the $3 \mathrm{SG}$ agreement whether the theme is personal or impersonal - i.e., the difference between 'real' agreement with pro and 'default' agreement with the similarly silent impersonal pronoun is obscured. Structurally, this would involve the collapsing of two functional projections into one:

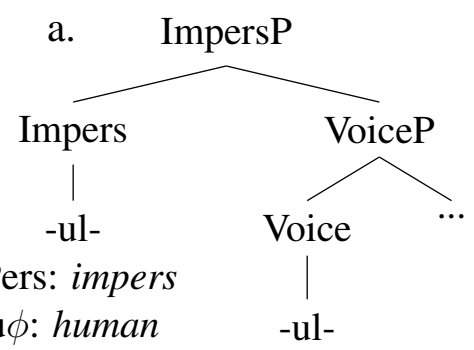

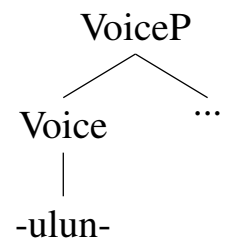

iVoice: pass

b.

iVoice: pass

Thus, an impersonal passive becomes a simple passive. This simplification of functional projections is well-motivated by learners' desire for structural economy in the absence of evidence for more articulated structure, as is often the impetus for syntactic diachronic change (Roberts \& Roussou 2003, van Gelderen 2011). This account has several explanatory points in its favour - for one, the reason why Sakha currently lacks a true impersonal passive is because the functional 'gap' left behind by the change in (36) has yet to be filled.

5.2. Phonology. Furthermore, this account explains the odd phonological distribution of Sakha as in Section 2.1. Consider again the allomorphs -(n)Ill-, found before vowels, and

\footnotetext{
${ }^{9}$ Doubled forms with impersonal passive or passive/middle interpretations exist in at least in middle Old Turkic (as a middle in Erdal (1991: 639)), Nogai (as a passive, cf. Csató (1998: 338), Turkish (as a impersonal passive, cf. Legate \& Akkus (2017)), Kazakh (as passives marginally, cf. Mukhamedova (2015: 212)), and according to our analysis Dolgan/Sakha -(I)l(I)n-.
} 
-(n)IllI-, found before [-alveolar] consonants. The second $/ / /$ in the geminate cluster cannot underlyingly be an $/ \mathrm{n} /$, because the regular assimilatory outcome of /-ln-/ clusters is [-nn-]: ${ }^{10}$

$$
\begin{aligned}
& \text { ilin-im } \rightarrow \text { inn-im 'my front' } \\
& \text { front-1SG }
\end{aligned}
$$

(with syncope of unstressed /i/)

(Anderson 1998: 18)

Contra Böhtlingk (1851), this suggests that -IlIn- must come from *-Il- + *-Il- with synchronic dissimilation, and not $*_{-} I l-+*$-In-. The change in (36) hence accounts for the rightmost/lower syllable originating as passive $*_{-}-I l-$, rather than reflexive $*_{-} I n-$. We can thus derive the surface allomorphy in Section 2.1 as follows:

$$
\begin{array}{ll}
\text { a. } & \text { /-IIIl-/ } \stackrel{\text { syncope }}{\longrightarrow} \text { /-Ill-/ } \\
\text { b. } & \text { /-IIII-/ } \stackrel{\text { syncope }}{\longrightarrow} \text { /-Ill-/ } \stackrel{\text { epenthesis }}{\longrightarrow} \text { /-IllI-/ } \\
\text { c. } & \text { /-IIIl-/ } \stackrel{\text { dissimilation }}{\longrightarrow} \text { /-IIIn-/ }
\end{array}
$$

(when before a vowel)

(when before a [-alveolar] C)

(elsewhere)

Before non-alveolar consonants (e.g. /b/), an epenthetic /I/ is inserted to break up the nonhomorganic consonant cluster. In contrast, alveolar consonants (e.g. /t/) assimilate fully to the nasality of the dissimilated morpheme-final $/ \mathrm{n} /$, producing a nasal geminate as in (2).

5.3. IMPLICATIONS FOR IMPERSP. Interestingly, (36) predicts that the impersonal passive was reanalysed as a passive only, and not necessarily a simple impersonal. Indeed, the semantic overlap with an active impersonal active is much less clear:

$$
\begin{array}{ll}
\text { a. } & \text { tut-ul-un-n-a. } \\
\text { catch-PASS-IMP-PST-3SG } \\
\text { '(Some)one was caught' } \\
\text { b. tut-ulun-n-a } \\
\text { catch-IMP-PST-3SG } \\
\text { 'One caught.' }
\end{array}
$$

(Pre-Sakha: Impersonal passive)

Unlike the pair in (35), the $\theta$-roles on the silent arguments in (39) are different; requiring a THEME and AGENT respectively. In order to explain the current ability of -IlIn- to have active impersonal meaning as well, it must be that the original impersonal morpheme *-Il- 'tagged along' when the passive morpheme *-Il- was replaced by -IIIn- as in (36). This lockstep shift is not predicted under an account where ImpersP and (passive) VoiceP are distinct projections with homophonous heads. Instead, it must be that impersonal passives involve the iteration of a single functional head VoiceP, where the difference between impersonal and passive meaning is derived from the value of the interpretable voice feature borne on the head and the presence/absence of a [+human] $\phi$-feature. We leave the full implications of this alternative view to future work, but seek to emphasise that diachronic evidence can provide key insight as to viability of proposed synchronic structures.

6. Conclusion. In sum, our paper has demonstrated that the Sakha morpheme -IlIn- is homophonous between impersonal and passive uses, but that these functions can be differentiated via cross-linguistically consistent syntactic diagnostics. At the same time, the oddly doubled synchronic surface form of this morpheme belies a complicated diachronic development pathway, involving reanalysis of a passive impersonal or 'passive of passive' construction (still at-

\footnotetext{
${ }^{10}$ We assume a phonological process of syncope whereby unstressed high vowels may be lost depending on adjacent consonants. Further study of this syncope must be conducted to confirm its exact conditioning environments.
} 
tested in modern Turkish.) By providing a new etymology for -IlIn- as largely unrelated to the reflexive/anti-causative morpheme, our analysis allows us to further articulate the Common Turkic voice system as well as question the functional status of ImpersP and (passive) VoiceP as distinct projections. All in all, this paper is an example of how the study of diachrony can illuminate apparently obscure aspects of the synchronic distribution of morphemes.

\section{References}

Anderson, Gregory D. S. 1998. Historical aspects of Yakut (Saxa) phonology. Turkic Languages 2(2). 1-32.

Baker, Mark C. 2015. Case: Its principles and its parameters. Cambridge: Cambridge University Press. http://dx.doi.org/10.1017/cbo9781107295186.

Baker, Mark C \& Nadya Vinokurova. 2010. Two modalities of case assignment: Case in Sakha. Natural Language \& Linguistic Theory 28(3). 593-642. http://dx.doi.org/10.1007/s11049-010-9105-1.

Berta, Árpd. 1998. Tatar and Bashkir. In Lars Johanson \& Csató Éva Ágnes (eds.), The Turkic Languages. 283-300. Routledge Handbooks. http://dx.doi.org/10.4324/9780203066102.

Boeschoten, Hendrik. 1998. Uzbek. In Lars Johanson \& Csató Éva Ágnes (eds.), The Turkic Languages. 357-378. Routledge Handbooks. http://dx.doi.org/10.4324/9780203066102.

Böhtlingk, Otto. 1851. Über die Sprache der Jakuten: Grammatik, Text und Wörterbuch. Vienna: Kaiserlichen Akademie de Wissenschaften.

Clark, Larry. 1998. Chuvash. In Lars Johanson \& Csató Éva Ágnes (eds.), The Turkic Languages. 434-452. Routledge Handbooks. http://dx.doi.org/10.4324/9780203066102.

Csató, É. Á. \& Karakoç, Birsel. 1998. Noghay. In Lars Johanson \& Csató Éva Ágnes (eds.), The Turkic Languages. 333-343. Routledge Handbooks. http://dx.doi.org/10.4324/9780203066102.

Danilova, Nadezhda I. \& Nadezhda I. Vinokurova. 2015. Two different approaches to Sakha passives. Journal of The Altaic Society of Korea (25). 117-131. http://dx.doi.org/10.15816/ask.2015..25.008.

Ebata, Fuyuki. 2013. Causative and passive in Sakha: Focusing on double-accusative causative and impersonal passive. Tomsk Journal of Linguistics \& Anthropology (2). 16-28.

Egerland, Verner. 2003. Impersonal pronouns in Scandinavian and Romance. Working Papers in Scandinavian Syntax 71. 75-102.

Erdal, Marcel. 1991. Old Turkic word formation: A functional approach to the lexicon, vol. 1. Otto Harrassowitz Verlag.

Erdal, Marcel. 2004. A Grammar of Old Turkic. Leiden: Brill.

van Gelderen, Elly. 2011. The Linguistic Cycle: Language Change and the Language Faculty. Oxford: Oxford University Press. http://dx.doi.org/10.1093/acprof:oso/9780199756056.001.0001.

Kavitskaya, Darya. 2010. Crimean Tatar. Munich: Lincom Europa.

Kiparsky, Paul. 2013. Towards a null theory of the passive. Lingua 125(1). 7-33. http://dx.doi.org/10.1016/j.lingua.2012.09.003.

Kirchner, Mark. 1998a. Kazakh and Karakalpak. In Lars Johanson \& Csató Éva Ágnes (eds.), The Turkic Languages. 318-332. Routledge Handbooks. http://dx.doi.org/10.4324/9780203066102. 
Kirchner, Mark. 1998b. Kirghiz. In Lars Johanson \& Csató Éva Ágnes (eds.), The Turkic Languages. 344-356. Routledge Handbooks. http://dx.doi.org/10.4324/9780203066102.

Kornfilt, Jaklin \& Omer Preminger. 2015. Nominative as no case at all: an argument from raising-to-accusative in Sakha. In Andrew Joseph \& Esra Predikac (eds.), Proceedings of the 9th Workshop on Altaic Formal Linguistics (WAFL 9), 109-120. Cambridge, MA: MIT Working Papers in Linguistics.

Legate, Julie Anne. 2014. Voice and v: Lessons from Acehnese. Cambridge, MA: MIT Press. http://dx.doi.org/10.7551/mitpress/9780262028141.001.0001.

Legate, Julie Anne \& Faruk Akkus. 2017. Turkish passive impersonals. Talk at the 48th North East Linguistics Society (NELS 48) University of Iceland, October 27-29.

Legate, Julie Anne, Faruk Akkuş, Milena Šereikaitė \& Don Ringe. 2020. On passives of passives. Language. To appear.

Mukhamedova, Raikhangul. 2015. Kazakh: A comprehensive grammar. Routledge.

Murphy, Andrew. 2014. Stacked passives in Turkish. Topics at InfL. 263-304.

Özkaragöz, İnci. 1986. Monoclausal double passives in Turkish. Studies in Turkish Linguistics. 77-91. http://dx.doi.org/10.1075/ts1.8.05ozk.

Özsoy, Ayse Sumru. 2009. Argument structure, animacy, syntax and semantics of passivization in Turkish: A corpus-based approach. In Yuji Kawaguchi, Makoto Minegishi \& Jacques Durand (eds.), Corpus analysis and variation in linguistics. 259-279. Amsterdam: John Benjamins Publishing. http://dx.doi.org/10.1075/tufs.1.16ozs.

Pesetsky, David \& Esther Torrego. 2007. The syntax of valuation and the interpretability of features. In Simin Karimi, Vida Samiian \& Wendy K. Wilkins (eds.), Phrasal and clausal architecture: Syntactic derivation and interpretation. 262-294. Amsterdam: John Benjamins Publishing. http://dx.doi.org/10.1075/la.101.14pes.

Roberts, Ian \& Anna Roussou. 2003. Syntactic change: A minimalist approach to grammaticalization. Cambridge: Cambridge University Press. http://dx.doi.org/10.1017/cbo9780511486326.

Róna-Tas, András. 1998. The reconstruction of Proto-Turkic and the genetic question. In Lars Johanson \& Csató Éva Ágnes (eds.), The Turkic Languages. 67-80. Routledge Handbooks. http://dx.doi.org/10.4324/9780203066102.

Schönig, Claus. 1998a. South Siberian Turkic. In Lars Johanson \& Csató Éva Ágnes (eds.), The Turkic Languages. 403-416. Routledge Handbooks. http://dx.doi.org/10.4324/9780203066102.

Schönig, Claus. 1998b. Turkmen. In Lars Johanson \& Csató Éva Ágnes (eds.), The Turkic Languages. 261-272. Routledge Handbooks. http://dx.doi.org/10.4324/9780203066102.

Stachowski, Marek \& Astrid Menz. 1998. Yakut. In Lars Johanson \& Csató Éva Ágnes (eds.), The Turkic languages. 417-433. http://dx.doi.org/10.4324/9780203066102.

Vinokurova, Nadezhda I. 2005. Lexical categories and argument structure: a study with reference to Sakha: Universiteit Utrecht dissertation. 